\title{
PERSPECTIVAS SIGNIFICATIVAS EM DANÇA CONTEMPORÂNEA: ARTE E CRIAÇÃO DE TUCA PINHEIRO
}

\section{Significant Perspectives in Contemporary Dance: art and creation of Tuca Pinheiro}

Nicole Blach Duarte

Universidade Estadual de Campinas - UNICAMP

Resumo: O presente artigo surge como resultado de uma residência com o artista Tuca Pinheiro e objetiva apresentar algumas de suas ideias sobre arte e criação em dança, tecendo conexões entre seus pensamentos e alguns princípios expressos no movimento do Judson Dance Theater. Espera-se compor perspectivas significativas em dança contemporânea, que possam ampliar discussões e trazer reflexões sobre seu "modo de existir" e de permanecer.

Palavras-chave: Dança contemporânea, arte, criação em dança.

Abstract: The present article comes as a result of a residence with the artist Tuca Pinheiro and aims to present some of his ideas about art and creation in dance, weaving connections between his thoughts and some principles expressed in the movement of the Judson Dance Theater. It is hoped to compose significant perspectives in contemporary dance, which can broaden discussions and bring reflections on their "way of existing" and staying.

Keywords: Contemporary dance, art, creation in dance. 
Tuca Pinheiro é um importante artista da dança na atualidade. Traz em suas obras assuntos polêmicos que abrangem os mais variados temas como política, sociedade, cultura, gênero, entre outros. Questionador e provocador, o artista já realizou diversos trabalhos pelo Brasil com grupos e companhias de renome tais como a Companhia de Dança do Palácio das Artes, o Balé Teatro Castro Alves, a Companhia de Dança do Teatro Guaíra e tem sido convidado a desenvolver oficinas e trabalhos coreográficos por todo o país.

\section{A residência artística com Tuca} Pinheiro foi realizada durante 0 período de montagem do espetáculo "PrimeiraPessoaDoPlural", criado em parceria com o coreógrafo Jorge Garcia para a Companhia de Dança do Palácio das Artes (BH-MG), e de apresentação da sua obra "Hyenna: não deforma, não tem cheiro e não solta tiras", na Fundação Nacional das Artes (FUNARTE - BH-MG).

A vivência de campo com Tuca Pinheiro seguiu $O$ modelo de observação assistemática (BONI; QUARESMA, 2005) e as entrevistas realizadas foram do tipo abertas e informais, pois tinham como objetivo aprofundar em questões já suscitadas pelo artista em outra entrevista realizada com ele ${ }^{1}$. Dessa maneira, a residência artística teve como objetivo compreender como Tuca Pinheiro articula na prática suas

1 Entrevista semiestruturada que resultou na produção de um artigo em coautoria, já aceito, apresentado e que aguarda publicação. concepções de arte, de dança e de criação em dança.

O presente artigo visa apresentar algumas ideias do artista sobre arte e criação em dança e tecer conexões entre seus pensamentos e alguns princípios expressos no movimento do Judson Dance Theater (Judson Dance). Consideramos que, identificar e estabelecer relações significativas entre as concepções e a prática artística de Tuca Pinheiro, poderá contribuir para ampliar a discussão e compreensão a respeito da dança contemporânea. A escolha de relacionar seus pensamentos com o Judson Dance deveu-se ao fato de terem sido encontradas aproximações entre a teoria-prática do artista e o movimento desse grupo da década de 1960.

Dialogando com autores que investigaram e apresentaram algumas noções de dança contemporânea (GADELHA, 2010; MURTA, 2014; TOMAZZONI, 2006) e com autores que discutem o movimento do Judson Dance Theater (BANES 1999; VIEIRA, 2013), serão apresentadas algumas ideias de Tuca Pinheiro, coletadas e observadas durante o período de residência, que abrangeu tanto seu trabalho enquanto coreógrafo/provocador no processo de criação para os bailarinos da Companhia de Dança do Palácio das Artes, quanto como artista bailarino da cena em seu próprio trabalho de criação.

Apresentaremos, com base nas interlocuções, uma breve reflexão, 
indicando um possível caminho para evitar o "engessamento" da dança contemporânea; questão muito presente em discussões sobre a caracterização deste "modo de fazer". Afinal, a estética da dança contemporânea vem se constituindo hoje como mais uma forma (ou fôrma) ou ainda preserva sua "identidade anárquica"?

\section{Dança contemporânea}

Um consenso que existe em relação à dança contemporânea é que não existe uma concepção unívoca sobre ela (JOSÉ, 2011; MURTA, 2014). Dependendo do aspecto observado no fenômeno, pode-se chegar a diversas possibilidades conceituais, que podem apontar para diferentes origens. Dessa maneira, se por um lado é possível pensar que nas propostas do Judson Dance "a dança contemporânea teve sua mais clara formulação de princípios" (TOMAZZONI, 2006 apud MURTA, 2014, p. 38), por outro, precisamos considerar que alguns autores elegem outras referências, tais como Louppe, que têm em Isadora Duncan um marco inicial (MURTA, 2014).

Vieira (2013) aponta que o movimento do início da década de 1960 impactou não apenas o mundo da dança conhecido até então, mas também todo o cenário das artes. No entanto, dado - caráter "anarquista" do movimento que, na dança, rompeu paradigmas e subverteu hierarquias de poder (a construção coletiva é um exemplo dessa subversão), é possível suspeitar que uma boa parte de suas relações com "o mundo atual" e com os modos de pensar-fazer dança não recebe uma atenção significativa e assim acabam por parecer, aos olhares menos engajados, "coisas" sem sentido, de uma "dança sem sentido". Para Banes:

Claramente, tanto as obras como a linguagem da vanguarda do início da década de 1960 (...) anunciam uma consciência transbordante (...). Esse ideal libertador foi compreendido como um todo ao final da década de 1960, mas nas de 1980, 1990, por todos os motivos econômicos e políticos, a efervescência é vista como uma ameaça, não como aspiração. (BANES, 1999, p. 308)

Uma vez que surgem múltiplos desdobramentos na dança, a partir dessa efervescência da década de 60 (BANES, 1999), há um risco eminente de "perder de vista" alguns princípios que impulsionaram a própria criação desses novos "modos da dança". Tornase fundamental buscar meios para que ela não seja submetida a modelos dogmáticos e de "domesticação", o que é claramente desprezado em qualquer perspectiva conceitual que se encontre sobre dança contemporânea. Por esse motivo, estabelecer relações significativas entre a prática de artistas de dança, suas concepções e contextos, pode contribuir para ampliar a compreensão e a discussão sobre as questões da dança contemporânea.

Ao perceber aproximações entre as concepções de Tuca Pinheiro sobre arte, dança e criação com alguns 
pressupostos evidenciados no movimento do Judson Dance Theater (BANES 1999; VIEIRA, 2013), tornouse coerente estabelecer esse, o ponto de partida. Contudo, ciente que, dada a pluralidade de conceitos em relação à dança contemporânea, que podem apontar para aspectos não contemplados neste trabalho, o presente texto reconhece suas limitações e se mantém aberto para novas formulações.

\section{Judson Dance, arte e criação em dança}

A Judson Church, uma igreja do Greenwich Village, em Nova lorque, Estados Unidos, foi o espaço onde alguns artistas exploraram novos modos de "fazer dança". O coletivo chamado Judson Dance Theater (Judson Dance) era formado por profissionais de diversas áreas da arte e teve como uma de suas vertentes a proposta de uma dança democrática, que pudesse abrir espaço para a criação coletiva, interdisciplinar, para pensar o corpo tanto em sua diversidade quanto em sua singularidade, e ampliar possibilidades de criação cênica. Para Muniz:

A partir da produção de dança do Judson, percebe-se o fim da "beleza", da "forma", do valor supremo e sublime da dança como arte. Desarticula-a atacando a própria definição de dança e revela o que Ihe foi estranho até então, utilizandose de todas as possibilidades para considerá-la poética sob todos os ângulos, entregando-se a sucessivas impressões a as traduzindo todas ao mesmo tempo. (...) Um desejo de liberdade estética, de liberdade no corpo, é, portanto, o fim da imposição de um estilo artístico, é o fim do engessamento estético e técnico da dança. (MUNIZ, 2011, p. 76)

Vieira (2013) aponta que um dos fatores mais adequados aos artistas da Judson Dance foi o abandono de narrativas, criação e "contação" de histórias. Seus propósitos estavam em provocar e questionar ideias. Nesse sentido, Tomazzoni afirma que:

A dança contemporânea reafirma a especificidade da arte da dança. Dança não é teatro, nem cinema, literatura ou música. Apesar de poder ganhar muito com a cooperação dessas artes. A dança não precisa de mensagem, de história e mesmo de trilha sonora. O corpo em movimento estabelece sua própria dramaturgia, sua musicalidade, suas histórias, num outro tipo de vocabulário e sintaxe. (TOMAZZONI, 2006)

Encontramos nessas afirmações de Tomazzoni uma grande "chave" para compreenderaproduçãocênicadadança contemporânea. Podemos incrementála ainda mais se considerarmos a atitude de "não espetacularização" da dança que fez com que os artistas da Judson Dance abandonassem o palco como estrutura fundamental, ampliando assim o espaço cênico para as ruas, estacionamentos, bares e etc. (VIEIRA 2013).

Promovendo discussões sobre os modos de se fazer dança, sobre a hegemonia de estilos técnicos, estéticos e corporais, esse coletivo de artistas 
quebrou referências elitistas da dança e buscou se aproximar das indagações sociais, políticas e epistemológicas da época. Podemos dizer que temos aí um primeiro indício da conexão entre Tuca Pinheiro e os artistas do Judson Dance. A dança para Tuca Pinheiro precisa essencialmente se colocar em diálogo com o mundo. Segundo o artista, o que o motiva na direção do processo de criação é a possibilidade de estabelecer esse diálogo e gerar uma obra que tenha alguma relevância nesse contexto.

Para o artista, a dança não é o lugar das "práticas assertivas", mas sim do desequilíbrio, da ineficiência, do erro. É nesse espaço "de imperfeição" que, para ele, existimos. Tuca Pinheiro ressalta a importância de nos compreendermos "não eficientes"; pois não somos máquinas e não podemos "funcionar" da mesma forma.

Fazendo essa relação entre dança e máquina (eficiente), ele nos remete à relação dança e corpo, redimensionando-o para além da esfera tecnicista e evocando a presença de um corpo humano, vivo, orgânico, que arriscamos pensar, em "estado de aprendizagem". Tuca Pinheiro não pensa a dança como uma ação que está fora do corpo. Ampliando as conexões, podemos pensar que o artista coaduna com o pensamento de Gadelha, quando diz que:

Fora do corpo que dança a dança não mais existe. É isso que possibilita os vários discursos que apontam a dança como uma "arte efêmera". Todo o agenciamento é in-carnado, só existe em corpo (...). A dança não é uma imagem do corpo como é, por exemplo, a representação anatômica; a dança é corpo. (GADELHA, 2010, p. 42)

Para Tuca Pinheiro, o corpo não é veículo. Ele é parte do processo e precisa estar disponível para a dança. Ele diz que "você não pode propor uma ideia se essa mesma ideia não está corporificada em você". Segundo o artista, algo que foge a essa premissa se configura como "pastiche"; uma imitação ruim. Tuca Pinheiro considera que processos onde a repetição não está a serviço do desenvolvimento de uma inteligência corporal constituemse como "adestramentos" físicos, que muitas vezes podem se apresentar como obstáculos para a criação em dança. Compreendendo a potencialidade do corpo, o artista se aproxima da ideia de corpo dos artistas do Judson Dance. Segundo Vieira:

(...) no Judson Dance Theater o sujeito é seu corpo, e o corpo não é mais o que o impede de aceder ao conhecimento, ele é fonte de prazer, de poder e de saber. (...) tal dança criou uma visão do corpo consciente, no qual a mente e o corpo já não eram mais divididos, mas harmoniosamente integrados. (VIEIRA, 2013, p. 9)

Criar, para Tuca Pinheiro, é correr riscos. Para ele, a arte não é o lugar das fórmulas prontas, da utilidade ou da conformação. Dessa maneira, o processo de criação precisa assumir 
sua contemporaneidade, que, para o artista, se relaciona com o pensamento de Agambem (2009) sobre ser contemporâneo:

Todos os tempos são para quem experimenta sua contemporaneidade, escuros. Contemporâneo é quem sabe ver essa sombra, quem está em condições de escrever (...) nas trevas do presente". (AGAMBEM, 2009, p. 62)

A criação, para Tuca Pinheiro, envolve adentrar o desconhecido e deixar-se conduzir pelo que surge nessa imersão. De acordo com Murta:

Na perspectiva de Tuca, o exercício constante da pesquisa é fundamental no pensamento contemporâneo e é justamente essa atitude de pesquisa que faz com que o artista mergulhe fundo numa questão, criando para tal (e por causa de, ao mesmo tempo) estratégias singulares que constroem corporalidades também singulares. (MURTA, 2013, p. 85)

Nesse sentido, entendemos que o artista assume o risco, pois acredita que, a partir dessa instabilidade gerada pelas incertezas, há uma substância capaz de dar forma e sentido àquilo que até então só existe em potencial. "(...) O risco é a competência que anima e que permite avançar" (HAMILTON apud LACINCE; NOBREGA, 2010, p. 247).

Podemos pensar que Tuca Pinheiro propõe a dança como processo do corpo, e assim necessita que o corpo (sujeito) encare a instabilidade, o "não controle", as incertezas e o erro, para dar passagem à obra e à corporalidade da obra. Essa proposta do artista pode ser comparada ao que Machado e Siedler apontam:

Um corpo que, ao dançar, se vale do que não é determinado como estratégia de composição, aprende, ao produzir soluções imediatas e inusitadas e ao experimentar a impossibilidade de uma repetição. Ao lidar com a incerteza, o corpo adquire complexidade e a intenção de enunciar uma falha é trocada pela ação de solucionar. É um exercício adaptativo que instiga o aprendizado, pois os ajustes do corpo enunciam engenhos particulares diante da incerteza presente nos processos. (MACHADO e SIEDLER, 2012, p. 5)

Propondo transgressões a padrões e normas estabelecidas, principalmente para/e no corpo, e provocando diferentes lógicas perceptivas, Tuca Pinheiro sugere 0 envolvimento total com 0 processo de criação; vivenciar, arriscar e ser transformado pela experiência. Experiência essa capaz de fazer surgir a obra e o corpo da obra.

Para o artista não existe técnica de dança contemporânea. Ele sugere que é possível pensar em técnicas contemporâneas de dança. Para Tuca Pinheiro, a dança contemporânea é um "modo de pensar a dança" e não pode se constituir como um modelo para organizar uma técnica ou uma estética específica. Essa atitude em si contraria a própria perspectiva que gerou esse "modo artístico". Uma vez que a dança contemporânea surge em 
decorrência de questionamentos sobre padronizações estéticas e técnicas de uma busca de ampliar possibilidades de criação, como ela poderia se "calcificar" como método específico?

Assim, ao discutir com o artista a maneira como a dança contemporânea vem sendo praticada e consumida, concordamos que existe um risco eminente (se é que já não está presente) de transformar a dança contemporânea em um modelo, uma forma, ou fôrma, engessando seus processos em busca de determinados resultados.

Durante 0 período de residência na montagem de "PrimeiraPessoaDoPlural", para a Companhia de Dança do Palácio das Artes, foi possível observar essa questão do "engessamento" nas possibilidades artístico-corporais e na estruturação da obra. Já em "Hyenna", trabalho solo de Tuca Pinheiro, foi possível perceber a maturidade e coerência do artista ao conseguir realizar, o que consideramos como, uma obra contemporânea de dança.

\section{Tuca Pinheiro e a criação em dança contemporânea}

Tuca Pinheiro conduziu o processo de criação para a Companhia de Dança do Palácio das Artes, partindo da ideia de coletivo. Esse é um de seus "princípios" para a criação em grupos e companhias de dança. Ele entende que é o comprometimento de todos os envolvidos no projeto que traz o sentido da obra. Nesse sentido, Tuca Pinheiro mantém a sintonia com os experimentadores da Judson, uma vez que, segundo Vieira:

\begin{abstract}
Para os dançarinos do Judson Dance, não havia relações hierárquicas no processo criativo, fossem de ordem estética (...) ou de ordem das relações entre os criadores. Orientados por questões que iam se colocando ao longo do processo, fundamentavamse em regras e estruturas que, por meio do jogo e da improvisação, iam formulando suas composições. (VIEIRA, 2013, p. 5)
\end{abstract}

Durante o processo de criação, o artista ia propondo discussões acerca da identidade do brasileiro e gerava dispositivos para a improvisação e para as construções cênicas. No entanto, observando as provocações de Tuca Pinheiro e as "respostas" corporais dos bailarinos, foi possível perceber o quanto é desafiador "vivenciar no corpo" a instabilidade e a abertura para "estados corporais de incerteza", propostos pelo artista.

O corpo do bailarino é um corpo treinado, que tem uma rotina de trabalho e que, dependendo da companhia, pode ser específica ou não. Na "Companhia de Dança do Palácio das Artes", apesar da intenção de explorar a diversidade, vista na flexibilização dos estilos de aulas e trabalhos que o grupo agrega, ainda predomina uma "linguagem" clássica na imagem corporal de muitos artistas. Desde a postura, até o domínio do gesto, para além da beleza de um corpo que constrói poéticas ao se 
mover, podemos perceber estruturas organizadas em certos padrões que necessitariam de mais tempo de imersão para serem "diluídos" de forma a dar passagem e deixar surgir "o tal corpo" que compreendemos ser o que Tuca Pinheiro busca em seu processo. Nem por isso o corpo que os artistas bailarinos modularam para a criação perdeu seu valor. Entretanto, observamos que a potência da experiência que o artista propôs para o processo de criação precisaria de tempo para encontrar seu próprio tempo de dar forma à obra.

Nesse sentido, refletimos sobre o quanto o período pré-estabelecido para a finalização do trabalho funcionou como um limitador dos processos. Se por um lado, o prazo contribui para organizar a produção do espetáculo, por outro, pressiona uma estruturação estética, que, sem tempo para "se fazer por si", acaba por recorrer aos velhos "modos" de ser. Dessa maneira, nós, espectadores, ficamos diante de uma mesma embalagem e precisamos estar muito disponíveis para enxergar nuances diferenciadas no conteúdo da obra.

Apesar dessas questões, o espetáculo "PrimeiraPessoaDoPlural" nos alcança. Jogando com a noção de coletivo, levada às vezes ao extremo, nos remetendo ora aos cardumes, ora às matilhas, compondo uma ideia de aglomeração, a obra nos apresenta uma visão de identidade brasileira atravessada por raças, crenças e história; modos da diversidade e da multiculturalidade que somos.

Em "Hyenna: não deforma, não tem cheiro e não solta tiras", trabalho solo de Tuca Pinheiro, percebe-se a maturidade e a coerência do artista diante de suas perspectivas, e a ideia de "engessamento" fica bem distante do que é visto em cena.

Tuca Pinheiro organiza o cenário, cuida de cada detalhe; luz, objetos, som. Enquanto confere os últimos detalhes técnicos, coloca uma música que fica de fundo, no ambiente. Nesse momento, ele se dirige a mim e conta que aquela música foi encontrada nos campos de concentração de Auschwitz. Foi escrita por um judeu em pedaços de papel que eram guardados no espaço entre os tijolos da parede.

O espetáculo "Hyenna" é sobre restos. Restos de roupas estão no palco. Roupas antigas, de pessoas conhecidas... Tuca Pinheiro tem um cocar, têm "pedaços" de roupas, peças de objetos. Ele não se aquece para dançar, não faz um tendu ou plié. Ele espreguiça, "solta o corpo", respira, inspira o ambiente. Ao fundo, uma música feita de restos.

A obra do artista é uma crítica cortante a tudo o que se refere à imposição, dominação, especulação, violação da integridade física, psíquica, emocional, mental e espiritual. É sobre invasão; é sobre a dormência do riso histérico dos que se alimentam desenfreadamente de restos (todos nós), sem parar para 
olhar e capturar a dimensão do que nos rodeia.

Tuca Pinheiroencara "o escuro" do tempo presente, permeado de restos e escreve sua obra. Partindo de um corpo múltiplo que se oferece nu, vestido, caricatural, poético, impregnado de códigos de dança, de gênero, de informações, de cultura. Ele compartilha, arrisca, tem a coragem de assumir e dar corpo aos seus pensamentos; seu trabalho é no mínimo coerente.

O espetáculo termina, e um misto de reflexão e tristeza paira no ar. Ao encontrar o artista nos bastidores, foi possível perceber a proporção de seu envolvimento com a obra. "Hyenna" é uma experiência intensa, que exige certo grau de disponibilidade para capturar a profundidade das questões presentes na cena. A obra é desagradável; maravilhosa, extremamente relevante.

O trabalho cênico de Tuca Pinheiro foi capaz de evidenciar seus apontamentos em relação à arte, à dança e à criação. Ele constrói um espetáculo contemporâneo de dança. As ideias do artista e a intencionalidade da obra estão presentes e são visíveis no corpo dele, na maneira como ele organiza as cenas, na dramaturgia. Nesse sentido, é válido refletir o quanto a distância entre o que se entende de dança contemporânea e o que se faz pode estar relacionada à dificuldade de compreender os saberes implícitos em seus "modos de existir" e de encarar a complexidade que a envolve.

\section{Considerações finais}

Com a crescente disseminação, indiscriminada de informações, festivais e concursos de dança, a dança contemporânea ainda preserva sua "identidade anárquica"? A suposta "essência"; aquilo que faz com que a dança seja dança contemporânea corre o risco de se perder em modos "padronizantes" que acabam por "formatar" o corpo e os processos de criação? Segundo Gadelha:
A dança contemporânea considera seu corpo-dançante não mais como instrumento a modelar, cuja matéria é neutra e inanimada, mas como uma fonte de movimentos únicos. O corpo- dançante parece, assim, "recém- revalorizado" no trabalho criativo da dança contemporânea. Recém, ou seja, recentemente, porque a dança contemporânea tem menos de um século. (GADELHA, 2010, p. 61)

Dessa maneira, podemos pensar em uma técnica de dança contemporânea? Um padrão estético pode nos apontar o que é ou não é dança contemporânea? Mas, por não se definir enquanto uma técnica, a dança contemporânea é uma dança sem técnica de dança?

Uma hipótese que surge em relação a alguns equívocos relacionados à dança contemporânea, tais como pensar que por não se definir em uma técnica específica, não prescinde de técnica, ou que em seu estilo "vale tudo", é a de que as transformações que a dança atravessou durante o processo de rupturas (que arriscamos 
dizer, começou no início do século XX e alcançou uma efervescência na década de 60) ocorreram nos contextos mais "especializados" de dança, entre artistas de alto nível de competência. Segundo Novak:

Toda atividade humana, quando levada a um estado de destreza suficiente, cria seus próprios conceitos, termos, palavras, acções e formas de trabalhar e de indagar que pura e simplesmente nos exclui, já que não estamos inseridos no contexto de acontecimentos, objetos, conceitos e factos acerca dessa atividade. (NOVAK, 1984, p. 26)

Nesse sentido, vale ressaltar que muitos dos movimentos "revolucionários" do início do século XX chamaram a atenção para uma visão de sociedade que não era muito "interessante" para os sistemas de poder. O Judson Dance, por exemplo, praticamente "inaugurou" um modo de organização horizontal, pautado na coletividade que desestruturou modelos hierárquicos na dança (VIEIRA, 2013). Contudo, esse tipo de organização foi proposto entre artistas notáveis da época. Dessa maneira, temos um paradoxo: uma "elite da dança" inaugura uma "dança democrática".

Acreditamos que no espaço entre essas duas polaridades é preciso construir uma ponte para que "todos" possam transitar. Para que o intercâmbio possa produzir novas perspectivas, é preciso que as partes envolvidas tenham certo tipo de alcance, ou maturidade intelectual/experiencial.

Dessa maneira, vale pensar em uma democratização da dança que potencialize os sujeitos na direção desse alcance, construindo espaço para ampliar o conhecimento na área. Possibilitar conexões entre os modos de fazer-pensar dança, e as implicações políticas sociais e culturais envolvidas em suas concepções, pode se apresentar como uma solução possível para reverter alguns equívocos presentes na dança contemporânea.

Entrar em "conformidade" e gerar padrões rígidos ou dogmáticos distancia a dança contemporânea da possibilidade de ser vivenciada enquanto um "sistema" passível de evolução, que, ao transgredir lógicas estabelecidas ou impostas e assumir a diversidade como possibilidade de trocas significativas, amplia espaços para a criação de novas maneiras de ser e existir. É nesse sentido que consideramos que a dança contemporânea é de natureza anárquica.

O que parece ser um caminho para não se "perder de vista" essa "essência" crítica, questionadora e provocadora da dança contemporânea é compreender suas dimensões tecendo relações significativas entre elas, investigar essas conexões e entender a técnica em dança como uma possibilidade de ampliar possibilidades de conhecer e expandir as interações com o mundo. 
Recebido em 24/05/2017

Aceito em 20/07/2017

\section{Referências Bibliográficas}

AGAMBEM, Giorgio. 0 que é contemporâneo? e outros ensaios. Chapecó, SC: Argos, 2009. 92 p. ISBN 978-85-7897-005-5.

BANES, Sally. Greenwich Village 1963: avant-garde, performance e o corpo efervescente - Rio de Janeiro: Rocco, 1999. 408 p. ISBN: 8532509800.

BONI, Valdeti; QUARESMA, Sílvia Jurema - Aprendendo a entrevistar: como fazer entrevistas em Ciências Sociais. Revista Eletrônica dos PósGraduandos em Sociologia Política da UFSC vol. 2 n 1 (3), 2005.

GADELHA, Rosa

Cristina

Primo. Corpografias em Dança Contemporânea. Tese (Doutorado) Universidade Federal do Ceará, Fortaleza - 2010.

JOSÉ, Ana Maria de São. Dança contemporânea: um conceito possível? In: COLÓQUIO INTERNACIONAL EDUCAÇÃO E CONTEMPORANEIDADE, 5., 2011, São Cristóvão. Anais eletrônicos... São Cristóvão: EDUCON, 2011, p. 1-12.

LACINCE, Nelly; NÓBREGA, Terezinha Petrúcia. Corpo Dança e Criação: conceitos em movimento. Movimento. Porto Alegre, v. 16, n. 03, 2010. ISSN 0104-754X.
MACHADO, Adriana Bittencourt; SIEDLER, Elke. A incerteza como índice de construção de autonomia em dança. Moringa. João Pessoa, v. 3 n. 2, 2012. ISSN 2177-8841.

MUNIZ,Zilá.Rupturaseprocedimentos da dança pós-moderna - O Teatro Transcende. Blumenau, v. 16, n. 2, 2011. ISSN: 2236-6644.

MURTA, Flor - Danças contemporâneas: articulando concepções e práticas de ensino. 2014. Dissertação (Mestrado em Dança) Universidade Federal da Bahia. Escola de Dança, Salvador, 2014.

Concepções de dança contemporânea: uma breve revisão. In: III ENCONTRO CIENTÍFICO NACIONAL DE PESQUISADORES EM DANÇA, 5., 2013, Salvador. Anais do... Salvador: Universidade Federal da Bahia, 2013, p. 1-19.

NOVAK, Joseph - Aprender a Aprender - Lisboa, Plátano: 1984. 190 p. ISBN972-707-137-6.

TOMAZZONI, Airton. Esta tal de dança contemporânea. Idanca.net. 2006. Disponível em: http://idanca.net/estatal-de-danca-contemporanea. Acesso em: 28 ago. 2015.

VIEIRA, Marcílio de Souza. Os experimentadores e seus pressupostos na Judson Dance Theater - Artciencia. com - Year VIII Number 16, 2013. ISSN 1646-3463. 
moringa 